\title{
Jonathan Boston
}

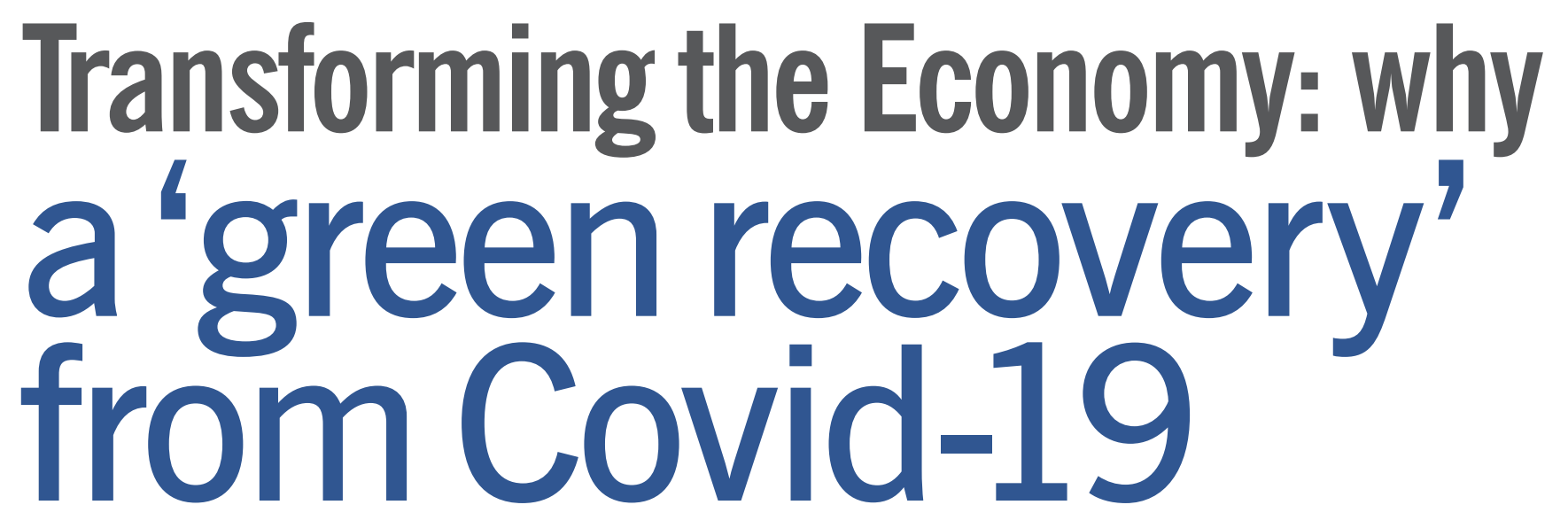

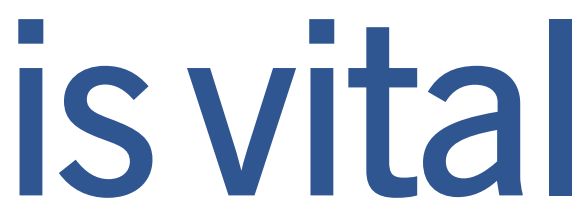

\section{Abstract}

The global ecological crisis poses much greater risks to humanity than Covid-19. At the same time, the pandemic provides a unique opportunity for governments to pursue a 'greener' and more sustainable future, for example through large-scale investments in clean energy sources, energy efficiency, waste reduction technologies, climateresilient infrastructure, regenerative agriculture and biodiversity protection. Yet, despite the urging of leading economists, ecologists and investors, measures to enhance ecological sustainability have not been prioritised in most governmental fiscal and regulatory responses to the pandemic. This article briefly summarises the nature of the current ecological crisis and, with particular reference to New Zealand, the policy measures required for an effective response. Fundamentally, a step change is needed from the current linear economy (based on finite energy sources and other non-renewable natural resources) to a more circular economy (based on renewable energy sources, the minimisation of waste and the efficient use of natural resources).

Keywords ecological crisis, green recovery, economic transformation, decarbonisation, circular economy

Jonathan Boston is Professor of Public Policy in the Wellington School of Business and Government at Victoria University of Wellington.
The Covid-19 pandemic has inflicted major economic harm globally. More grim news is likely, especially regarding unemployment. But humanity faces much greater and more protracted harm if it fails to live within safe biophysical limits. Currently, many safe limits are being exceeded at multiple scales - global, regional, national and local (Rockström et al., 2009; Steffen et al., 2015; IPCC, 2018). For a genuinely sustainable and inclusive future, a radical transformation of the global economy is urgently required (Harvey, 2020; Hagens, 2020; Hepburn et al., 2020; UNEP, 2019). Given its natural endowments and competent democratic governance, New Zealand should be at the forefront of this transformation. Sadly, with a few notable exceptions, it is not (see Blaschke, 2020; Hall, 2019; Productivity Commission, 2018; OECD, 2017).

This article comments briefly on the nature and scale of the ecological crisis facing humanity, noting in particular New Zealand's indifferent, if not poor, environmental record, and explains why a 'green' recovery from the pandemic is vital. It then outlines the principles that should inform the quest for a more sustainable and resilient economy, highlighting some of the specific policy reforms required in New Zealand. This includes a brief discussion of an idea gaining prominence internationally 
about shifting from a linear to a circular economy (Climate Change Committee, 2020; Kornhonen, Honkasalo and Seppälä, 2018).

\section{The ecological crisis}

From an ecological perspective, the main global challenges include the growing risk of dangerous climate change, an unprecedented and escalating loss of biodiversity, increasing levels of atmospheric, terrestrial and marine pollution, massive deforestation, and significant soil retrogression and degradation. Most of these problems are interconnected; they are all well documented by the international scientific community. Without urgent, comprehensive and sustained international efforts, the Earth will become increasingly less hospitable for human habitation. Critical tipping points will be crossed, inflicting irreversible damage. Future generations deserve better. Our 'common home', as Pope Francis calls it, must be protected.

While New Zealand celebrates its 'clean and green' image, serious ecological problems in multiple domains are evident. ${ }^{1}$ Both gross and net greenhouse gas emissions have risen significantly over recent decades due to land-use change, the intensification of dairying and rising land transport emissions. The long-term loss of native forests and wetlands continues, as does the loss of soil due to erosion, urbanisation and poor land-use management. Many of the country's unique freshwater species, habitats and ecosystems are endangered, with around three-quarters of native freshwater fish threatened with, or at risk of, extinction. Similarly, of marine species assessed, some $90 \%$ of seabirds, $80 \%$ of shorebirds and $22 \%$ of marine mammals are under threat or at risk of extinction. To compound matters, New Zealand produces a high volume of waste per capita and has barely begun to address the problem. Meanwhile, water pollution affects numerous rivers, aquifers, lakes and estuaries. And so the list could go on.

\section{Climate change}

Climate change is particularly concerning because of its widespread, severe and
... given

New Zealand's

relatively high

per capita annual

emissions of $\mathrm{CO}_{2}$

and other

greenhouse gases, together with

high cumulative

emissions per capita, basic principles of distributive justice suggest that this country should be making a greater than average global effort.

often irreversible impacts, as highlighted by recent reports of the Intergovernmental Panel on Climate Change (see IPCC, 2018). The Paris Agreement of 2015 commits the international community to implementing measures to limit the global average temperature to 'well below $2^{\circ} \mathrm{C}$ above preindustrial levels' and ideally to no more than $1.5^{\circ} \mathrm{C}$ above pre-industrial levels. Such goals are extremely demanding. The Earth's mean surface temperature has already increased by at least $1.0^{\circ} \mathrm{C}$ since the 19th century. To remain within the $1.5^{\circ} \mathrm{C}$ warming cap (i.e. with little or no overshooting), global net anthropogenic carbon dioxide $\left(\mathrm{CO}_{2}\right)$ emissions must fall by around 45\% from 2010 levels by 2030 (i.e. about 7\% per annum) and reach zero by around 2050 (ibid., p.14). To limit global warming to below $2{ }^{\circ} \mathrm{C}$, $\mathrm{CO}_{2}$ emissions must fall by about $25 \%$ by 2030 and reach zero by about 2070. Such scenarios also require deep reductions in non- $\mathrm{CO}_{2}$ emissions (e.g. methane and nitrous oxide).

Three caveats deserve immediate mention. First, there is nothing 'safe' about global average temperature increases of $1.5^{\circ} \mathrm{C}$ or $2^{\circ} \mathrm{C}$ (IPCC, 2018). A rise of these magnitudes is consistent with, among other things, a multi-metre increase in the sea level over the coming centuries. This would cause enormous damage to coastal cities, public infrastructure and ecosystems.

Second, a recent assessment by the United Nations Environment Programme (2019) paints a bleak picture. In the decade to 2018 , greenhouse gas emissions rose $1.5 \%$ per annum on average, reaching a record high in 2018 of $55.3 \mathrm{Gt} \mathrm{CO}_{2}$ e. Worse, the emissions-reduction commitments of the global community since the Paris Agreement fall far short of those required to remain within a $2^{\circ} \mathrm{C}$ warming cap, let alone a $1.5^{\circ} \mathrm{C}$ cap. Indeed, they are consistent with an average increase of more than $3^{\circ} \mathrm{C}$ by 2100 . For global emissions to fall quickly, aggressive policy measures by the major economies and massive private sector investment in renewable technologies are essential.

Admittedly, Covid-19 may depress emissions during 2020, with global $\mathrm{CO}_{2}$ emissions falling by an estimated $17 \%$ in April 2020 (Harvey, 2020; Le Quéré et al., 2020) and closer to $40 \%$ in New Zealand. But any reduction generated by behavioural rather than systemic changes might be only temporary. Moreover, evaluations of global policy responses to the pandemic suggest that few of the massive fiscal stimulus packages announced thus far (estimated at close to US\$9 trillion) will reduce greenhouse gas emissions or enhance other environmental goals (Hepburn et al., 2020; IEA, 2020). Indeed, significant additional investment in carbon-intensive infrastructure, together with high-carbon production and consumption goods, now seems likely. If so, an unprecedented global opportunity to accelerate the transition to a low-carbon economy will be missed.

Third, recent findings from leading international climate modelling teams, including the Hadley Centre at the UK Met Office, point to the climate system being more sensitive to changes in atmospheric concentrations of $\mathrm{CO}_{2}$ than previously thought (Palmer, 2020; Watts, 2020; Williams, Hewitt and Bodas-Salcedo, 2020). Climate sensitivity refers to the amount of warming expected from a sustained doubling of atmospheric 
concentrations of $\mathrm{CO}_{2}$ (i.e. from 280 parts per million (ppm) in the pre-industrial period to 560ppm; they are currently about $417 \mathrm{ppm})$. Until recently climate sensitivity was estimated at $3^{\circ} \mathrm{C}$. But, as knowledge of the microphysics of clouds improves, there is evidence that climate sensitivity may be closer to $5^{\circ} \mathrm{C}$. It is too early for firm conclusions, but if such findings are correct they would be deeply concerning. Keeping within a $2^{\circ} \mathrm{C}$ warming cap, let alone a lower cap, would then be all but impossible.

New Zealand's greenhouse gas emissions comprise only a tiny fraction of global emissions (about 0.17\%). But, despite a heavy reliance on renewable energy sources for electricity, gross $\mathrm{CO}_{2}$ emissions were 7.7 tonnes per capita in 2017 (close to the developed world average, but well above the global average of about 5 tonnes), while gross $\mathrm{CO}_{2} \mathrm{e}$ emissions (i.e. including non- $\mathrm{CO}_{2}$ gases such as methane and nitrous oxide) were 17.2 tonnes per capita, which is the sixth highest in the developed world (Ministry for the Environment, 2020, p.6).

Policy measures to reduce greenhouse gas emissions in recent decades have been ad hoc, modest and largely ineffectual. To be sure, the current Labour-led government has enacted legislation - the Climate Change Response (Zero Carbon) Amendment Act 2019 - which sets an ambitious target of net zero emissions for all greenhouse gases (other than biogenic methane) by 2050 and a lesser target to reduce biogenic methane emissions by $24-47 \%$ by 2050 (relative to 2017). It has also strengthened the Emissions Trading Scheme (e.g. by placing a cap on the total allowed emissions under the scheme), and implemented various other measures to reduce emissions (e.g. via greater investment in clean transport options).

But existing policy settings are not consistent with the 2050 emissionsreduction targets. Nor will they achieve anything like a $45 \%$ reduction in net $\mathrm{CO}_{2}$ emissions by 2030 (compared to 2010 levels) - which, as noted, the IPCC estimates is necessary to have a reasonable chance of avoiding warming of more than $1.5^{\circ} \mathrm{C}$ (IPCC, 2018). Moreover, given New Zealand's relatively high per capita annual emissions of $\mathrm{CO}_{2}$ and other greenhouse gases, together with high cumulative
Any 'green recovery' ... will require the systematic integration of economic, social and environmental policies[, in] particular, effective policy measures will be needed to assist those citizens and communities least able to cope with major adjustments to relative prices and disruptive
technologies ...

emissions per capita, basic principles of distributive justice suggest that this country should be making a greater than average global effort.

Aside from this, New Zealand has barely begun to prepare for the enormous impacts of climate change during the 21st century and beyond, including sea level rise, more severe storms and more protracted droughts (see, for instance, Ministry for the Environment, 2017). Huge investments in more resilient public infrastructure, such as water services and transportation networks, and the relocation of numerous coastal settlements will be required over the coming decades.

Climate change, of course, is only one of multiple, interconnected ecological issues - such as biodiversity loss, water pollution, land degradation and plastic waste - which must be tackled urgently. A systematic effort to address such problems will require major policy changes, globally and locally. Few of these will be easy politically to implement, not least because of the power of vested interests, the fiscal costs entailed and the likely distributional impacts. But a failure to act now will simply increase the financial and non-financial costs borne by future generations.

\section{Goals and principles for a post-Covid-19 recovery}

Crises create opportunities. Covid-19 provides an opportunity to reorient economic policy globally for greater environmental sustainability. First, the pandemic has created an urgent need for a major boost in public expenditure to help maintain overall economic activity, including both consumption and investment. Second, the pandemic has been hugely disruptive, both socially and economically - dislocating wellestablished supply chains, altering patterns of work and social interactions, disrupting major industries (e.g. aviation, tourism and the hospitality sector), and generating substantial pockets of unemployment and underutilised capital. These impacts, in turn, create the conditions for policy innovation and reform - but only if governments have the foresight and willingness to act.

For policymakers open to a transformative recovery rather than business as usual, much authoritative advice is available. Responding to the pandemic, numerous international organisations (e.g. the International Energy Agency, OECD, IMF and World Bank), leading think tanks, major research organisations and independent governmental agencies (e.g. climate change committees and environmental commissions) have published a raft of strategies and agendas for a 'green recovery.' While the proposals differ in certain respects, there is general agreement on the core policy objectives. These include working towards achieving the United Nations Sustainable Development Goals by 2030, keeping faith with the Paris Agreement, pursuing concerted efforts to protect biodiversity and restore nature, and enabling a just transition to a zero-emissions economy. Equally, there is general agreement on the policy reforms required for a more sustainable future. Key measures include:

- substantial public investments in clean technologies and climate-resilient infrastructure; 
- regulatory measures to speed up the decarbonisation of stationary energy systems and transportation;

- policies to promote sustainable production and consumption, including the proper pricing of environmental externalities;

- measures to improve land management and carbon sequestration; and

- greater public expenditure on research, innovation and training in low-carbon products, processes and services.

In New Zealand, the global calls for a green recovery have been echoed by numerous business leaders, nongovernmental organisations, researchers and independent public bodies. For instance, the Climate Change Commission, in a series of letters to the minister for climate change, James Shaw, has outlined how the government's economic response to the pandemic could help mitigate climate change and adapt to its impacts. Six principles were enunciated in the commission's first letter (Climate Change Commission, 2020a), and can be summarised as follows:

1. Consider how stimulus investments can deliver long-term climate benefits (e.g. by future-proofing investments in infrastructure, avoiding investments in long-lived assets that lock in high emissions or generate stranded assets, and applying a climate lens to spatial planning decisions).

2. Bring forward transformational climate change investments that need to happen anyway.

3. Prepare our workforce for the jobs of tomorrow in a low-emissions and climate-resilient economy and society (e.g. by investing in education and training and revitalising educational institutions affected by the pandemic).

4. Work in partnership with key stakeholders to enhance change and innovation (e.g. with iwi/Māori, consistent with the principles of te Tiriti o Waitangi, with businesses to leverage private sector action and finance, and with the research community to identify new opportunities and tools).

5. Maintain incentives to reduce emissions and adapt to climate change (e.g. by ensuring that market, regulatory and
... the reform agenda must extend well beyond decarbonisation and adaptation to climate change.

policy measures are aligned with longterm climate change goals, including a clear and credible signal for lowemissions investment through the Emissions Trading Scheme).

6. Change how the success of the economic recovery is measured (e.g. through utilising a broad range of wellbeing indicators that sit alongside the traditional economic indicators).

While these principles have undoubted merit, several additional considerations warrant attention. Any 'green recovery' must give proper weight to principles of distributive justice. Hence, the process must be not only fast, but also fair (see Boston and Hall, 2019; Productivity Commission, 2018, pp.271-99). This will require the systematic integration of economic, social and environmental policies. In particular, effective policy measures will be needed to assist those citizens and communities least able to cope with major adjustments to relative prices and disruptive technologies (e.g. through reforms to the tax-benefit system and active labour market policies).

\section{Towards a circular economy}

Next, the reform agenda must extend well beyond decarbonisation and adaptation to climate change. It must also address the many other environmental challenges facing the country, as outlined earlier. In effect, this means shifting from a linear to a circular economy. A linear economy relies heavily on non-renewable energy sources and other non-renewable natural resources. In terms of resource use, the approach is one of 'take, make and dispose'. But without a full accounting for, and proper costing of, environmental externalities, such an approach is inefficient. Invariably it results in a high volume of waste, degradation of the terrestrial and marine environment, and damage to multiple ecosystem services. Ultimately, a linear economy will undermine vital planetary life-support systems.

By contrast, a circular economy involves operating within safe biophysical limits, at multiple scales and across all economic domains. ${ }^{3}$ To be sure, the concept of the circular economy continues to evolve; nor is it without problems or critics (Geissdoerfer et al., 2017; Kornhonen, Honkasalo and Seppälä, 2018; Millar, McLaughlin and Börger, 2019). Nevertheless, the concept embraces at least five key features, all of which merit attention.

First, central to the idea of circularity is that economic activity must be decoupled from the continuous extraction and consumption of finite, non-renewable resources, such as fossil fuels. Instead, the economy must rely on renewable energy sources and, wherever possible, materials from renewable sources (e.g. food, fibres and wood). This means living within the regenerative capacity of the planet's natural resources.

Second, a core aim is to design all forms of waste out of the systems of production and consumption. This entails keeping most material resources 'circulating' in a 'cradle-to-cradle life cycle' for as long as possible, with any waste products serving as 'food' for other economic processes. This process is applicable to every form of economic activity (e.g. agriculture, manufacturing and construction) and all types of goods and services (e.g. food, clothing, furniture, equipment, vehicles and infrastructure).

Third, a circular economy involves extracting the maximum value from material resources while they are in use, followed by processes of recovery and regeneration (e.g. this may include, depending on the circumstances, reuse, repair, remanufacture, refurbishment, recycling, composting and reverse cycles). The goal, in other words, is not only ecological sustainability but also the most efficient and effective use of material resources. Productivity improvement 
through technological innovation is thus central to a circular economy.

Fourth, a key goal is to restore, rebuild and improve the full range of capital stocks on which human civilisation depends, including natural, human, social and manufactured capital, in the interests of better economic, social and environmental outcomes. Given the amount of damage already inflicted, the process of restoring various natural capital stocks will be long and arduous.

Finally, moving to a circular economy means embedding a long-term perspective - one that gives proper weight to intergenerational fairness, risk management and ecological values - in all areas of economic policymaking. This must include spatial planning, industry policy, energy policy, transport policy, infrastructure investment, building and construction, housing, procurement and tourism. Commitment devices, institutional arrangements and analytical frameworks that incentivise sound intertemporal governance rather than short-termist policies are vital (Boston, 2017).

\section{Securing an economic step change towards sustainability}

While the overall destination of a more resilient, inclusive and circular economy can be readily specified (at least in broad terms), how best to undertake the journey is less clear. There are multiple barriers, not least entrenched interests, limited public knowledge and understanding, significant conceptual challenges, and complex technical and policy issues (Galvãoa et al., 2018; Millar, McLaughlin and Börger, 2019). A systematic roadmap of the required fiscal, regulatory and other policy reforms required is not possible here; some brief suggestions must suffice. More comprehensive accounts are readily available (see, for instance, Blaschke, 2020; Climate Change Committee, 2020; Productivity Commission, 2018; Royal Society of New Zealand, 2016).

For New Zealand to embrace a circular economy, at least two steps are critical decarbonisation and waste minimisation. In both cases there is considerable scope to harness funding from the Covid-19 fiscal stimulus package and the Provincial Growth Fund.

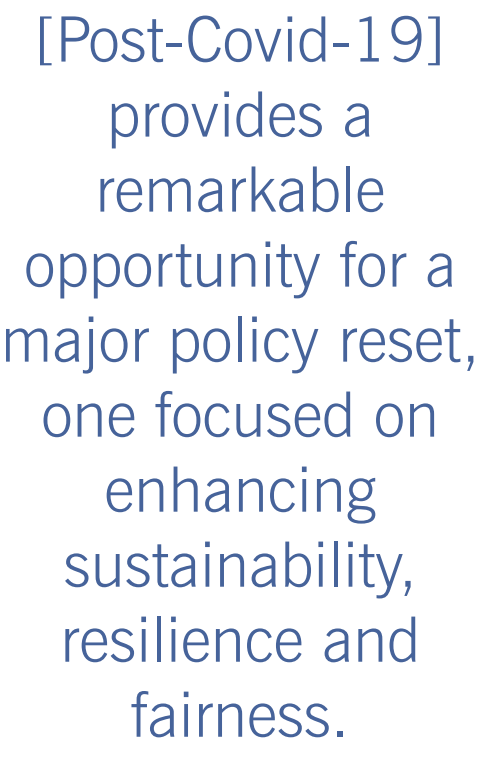

Decarbonising land transport

With respect to decarbonisation, land transport accounts for around 20\% of the country's greenhouse gas emissions or close to $40 \%$ of $\mathrm{CO}_{2}$ emissions (see Productivity Commission, 2018). Of these emissions, $75 \%$ are from light vehicles, with close to $60 \%$ from passenger vehicles and the rest from light commercial vehicles. These emissions could be eliminated over the coming decades through a greater reliance on public transport and active transportation modes (i.e. cycling and walking), car sharing schemes, and the progressive electrification of the light vehicle fleet. The required technologies for electrification are readily available; they simply need to be applied. Various policy reforms could speed up this process (see Barton and Schütte, 2017; Bhardwaja et al., 2020), including some mix of the following measures:

- introducing effective regulatory standards for fuel economy and $\mathrm{CO}_{2}$ emissions;

- introducing a feebate scheme with rebates for low-emissions vehicles and extra charges for high-emissions vehicles (e.g. as in France and Sweden);

- banning the purchase of new vehicles with internal combustion engines beyond a specified date (e.g. Norway has set a date of 2025, the UK 2035);

- requiring all light vehicles to be emissions free by a specified date (e.g. the Netherlands has set a date of 2030); and
- developing a more comprehensive electric vehicle (EV) charging network, including requiring all petrol stations to install EV charging equipment (e.g. as in Germany).

At the same time, appropriate regulations must be implemented to ensure that all EV components, not least the batteries, are reusable or recyclable. This leads naturally to the critical topic of waste.

\section{Minimising waste}

New Zealand is among the most wasteful societies per capita. The country's waste management and recycling systems are weak, fragmented and inconsistent. Admittedly, a comprehensive and progressive Waste Minimisation Act was enacted over a decade ago (2008), but its provisions have yet to be properly applied (Blumhardt, 2018). Numerous policy reforms are needed if resources are to be better utilised and waste minimised. Priorities must include:

- encouraging investment in systems and processes for waste prevention, including regulatory reform to incentivise product redesign for modularity, repairability and upgradability. The aim must be to design waste out of the system, preferably at the top of supply chains by ensuring the reuse of materials (e.g. via reusable packaging and sterilisation infrastructure) rather than recycling;

- extending the government's waste work programme proposals, including raising the waste disposal levy and implementing regulated product stewardship schemes;

- phasing out single-use disposable items and difficult to recycle products, such as composite materials and certain plastic polymer types;

- encouraging a greater reliance on the sharing economy for items such as cars, electronics and appliances;

- encouraging investment in a nationwide network of decentralised composting and vermicomposting systems for organic waste, as well as paper and cardboard waste that cannot be recycled onshore;

- requiring consistent waste management and recycling collections across New Zealand, including standardising 
accepted materials, and moving towards source-separated recyclate collections rather than commingled collections; and

- requiring high sustainability standards in the building and construction industry, including waste minimisation and resource recovery. ${ }^{4}$

\section{Enhancing climate resilience}

Finally, preparing for the impacts of climate change - including sea level rise, more powerful storms and more severe droughts - is crucial. Substantial public investment will be required in climateresilient public infrastructure, including upgrading and relocating water services and coastal transport networks, and improving water storage for urban and agricultural uses. In the wake of Covid-19, investing now for a more secure future makes sense.

\section{Conclusion}

Human-induced environmental change is gathering pace. The risk of catastrophic ecological impacts is growing. The time frame within which to avert such outcomes is short. The Covid-19 pandemic is a defining moment. It provides a remarkable opportunity for a major policy reset, one focused on enhancing sustainability, resilience and fairness. Seizing the opportunity for a 'green recovery' is vital economically, socially and environmentally, both here in $\mathrm{New}$ Zealand and globally.

\footnotetext{
1 For details, see OECD, 2017, and the growing volume of domain and synthesis reports produced by the Ministry for the Environment and Stats NZ, as required under the
}

Environmental Reporting Act 2015.

2 See, for instance, Climate Change Commission, 2020a, 2020b; Climate Change Committee, 2020; Environmental Justice Commission, 2020; International Energy Agency, 2020; Productivity Commission, 2018.

3 For a brief overview of the circular economy, see https:// www.ellenmacarthurfoundation.org/circular-economy/whatis-the-circular-economy.

4 Of relevance here are: the resources and tools of REBRI (Resource Efficiency in the Building and Related Industry); the Infrastructure Sustainability Council of Australia rating system; the New Zealand Green Building Council's green star ratings; the New Zealand Ecolabelling Trust's environmental choice specifications; and the requirements in London for planning applications to include a circular economy statement demonstrating how building components can be disassembled and reused.

\section{Acknowledgements}

The author would like to thank Barry Barton, Hannah Blumhardt, Trevor Drage, Grant Duncan, Michael Fletcher and Janet Stephenson for their help and advice in preparing this article.

\section{References}

Barton, B. and P. Schütte (2017) 'Electric vehicle law and policy: a comparative analysis', Journal of Energy and Natural Resources Law, 35 (2), pp.147-70

Bhardwaja, C. et al. (2020) 'Why have multiple climate policies for light-duty vehicles? Policy mix rationales, interactions and research gaps', Transportation Research Part A, 135, pp.309-26

Blaschke, P. (2020) 'Integrating land use options for the Aotearoa New Zealand low-emissions "careful revolution"', Policy Quarterly, 16 (2), pp.26-34

Blumhardt, H. (2018) 'Trashing waste: unlocking the wasted potential of New Zealand's Waste Minimisation Act', Policy Quarterly, 14 (4), pp.13-26

Boston, J. (2017) Governing for the Future: designing democratic institutions for a better tomorrow, Bingley: Emerald

Boston, J. and D. Hall (2019) 'Appendix 1: proposed principles of justice', in D. Hall (ed.), The Careful Revolution, Wellington: Bridget Williams Books

Climate Change Commission (2020a) 'Letter to Hon James Shaw', 7 April

Climate Change Commission (2020b) 'Letter to Hon James Shaw', 19 May

Climate Change Committee (2020) Reducing UK Emissions: 2020 progress report to Parliament, London

Environmental Justice Commission (2020) Faster, Further, Fairer: putting people at the heart of tackling the climate and nature emergency, London: Institute for Public Policy Research

Galvãoa, G. et al. (2018) 'Circular economy: overview of barriers', ScienceDirect, 73, pp.79-85

Geissdoerfer, P. et al. (2017) 'The circular economy: a new sustainability paradigm?', Journal of Cleaner Production, 143, pp.757-68

Hagens, N. (2020) 'Economics for the future: beyond the superorganism', Ecological Economics, 169

Hall, D. (ed.) (2019) The Careful Revolution, Wellington: Bridget Williams Books

Harvey, F. (2020) 'World has six months to avert climate crisis, says energy expert', Guardian, 18 June

Hepburn, C. et al. (2020) 'Will COVID-19 fiscal recovery packages accelerate or retard progress on climate change?', working paper 20-02, Oxford: Smith School of Enterprise and the Environment

IEA (2020) Sustainable Recovery: world energy outlook special report, Paris: International Energy Agency
IPCC (2018) 'Summary for policymakers', in Global Warming of $1.5^{\circ} \mathrm{C}$, Geneva: IPCC

Kornhonen, J., A. Honkasalo and J. Seppälä (2018) 'Circular economy: the concept and its limitations', Ecological Economics, 143, pp.37-46

Le Quéré, C. et al. (2020) 'Temporary reduction in daily global CO2 emissions during the COVID-19 forced confinement', Nature Climate Change, 10, pp.647-53

Millar, N., E. McLaughlin and T. Börger (2019) 'The circular economy: swings and roundabouts?', Ecological Economics, 158, pp.11-19

Ministry for the Environment (2017) Coastal Hazards and Climate Change: guidance for local government, Wellington: Ministry for the Environment

Ministry for the Environment (2020) New Zealand's Greenhouse Gas Inventory 1990-2018: snapshot, Wellington: Ministry for the Environment

Ministry for the Environment and Stats NZ (2020) Our Freshwater 2020, Wellington: Ministry for the Environment and Statistics New Zealand

OECD (2017) OECD Environmental Performance Reviews: New Zealand 2017, Paris: OECD

Palmer, T. (2020) 'Short-term tests validate long-term estimates of climate change', Nature, 582, pp.185-6

Productivity Commission (2018) Low-Emissions Economy: final report, Wellington: New Zealand Productivity Commission

Rockström, J. et al. (2009) 'Planetary boundaries: exploring the safe operating space for humanity', Ecology and Society, 14 (2)

Royal Society of New Zealand (2016) Transition to a Low-Carbon Economy for New Zealand, Wellington: Royal Society of New Zealand

Steffen, W. et al. (2015) 'Planetary boundaries: guiding human development on a changing planet', Science, 347 (6223)

UNEP (2019) Emissions Gap Report 2019, New York: United Nations Environment Programme

Wainwright, O. (2020) 'The case for ... never demolishing another building', Guardian, 13 January

Walker, P. (2020) 'Lib Dems unveil £150bn green coronavirus recovery plan', Guardian, 18 June

Watts, J. (2020) 'Climate worst-case scenarios may not go far enough, cloud data shows', Guardian, 13 June

Williams, K.D., A. Hewitt and A. Bodas-Salcedo (2020) 'Use of short range forecasts to evaluate fast physics processes relevant for climate sensitivity', Journal of Advances in Modeling Earth Systems, 12 (4) 